\title{
Genetic background of resistance to gall mite in Ribes species
}

\author{
Ingrida Mazeikiene, Vidmantas Bendokas, Danas Baniulis, Grazina Staniene, Dovile Ana Juskyte, Audrius Sasnauskas, \\ Vidmantas Stanys, Tadeusas Siksnianas \\ Institute of Horticulture, Lithuanian Research Centre for Agriculture and Forestry, Kauno 30, LT-54333 Babtai., Kaunas distr., \\ Lithuania \\ e-mail: i.mazeikiene@Isdi.It
}

\begin{abstract}
Resistance to gall mite is an important genetic trait of Ribes. $P$ and $C e$ genes, responsible for gall mite resistance, were established in Ribes species and interspecific hybrids using molecular markers. Resistance in $R$. americanum is determined by $P$ gene and in $R$. sanguineum by $C e$ gene. Both molecular markers were absent in $R$. dikuscha genome. Molecular markers related to $P$ and $C e$ genes were identified in the genome of $R$. aureum. Resistance to gall mite in the field conditions in $R$. nigrum $\times R$. americanum, $R$. nigrum $\times R$. aureum and $R$. nigrum $\times R$. sanguineum $F_{3}$ hybrids fitted an expected Mendelian segregation ratio of $1: 1,3: 1$ and $1: 1$, respectively. $75.0 \%$ of hybrids with a pyramidal resistance to gall mite carrying markers related to $C e$ and $P$ genes were obtained in the cross combination $R$. nigrum $\times R$. aureum and will be included in the future breeding programs.
\end{abstract}

Key words: Cecidophyopsis ribis, Ce gene, $P$ gene, resistance.

\section{Introduction}

Blackcurrant (Ribes nigrum L.) is one of the most important fruit crops in Europe, including Lithuania. Blackcurrant gall mite (Cecidophyopsis ribis Westw.) damages floral buds and is a vector of blackcurrant reversion virus (BRV) (Jones 2000). Gall mite infection causes heavy losses in blackcurrant production (Šutic et al. 1999).

Several sources of resistance to gall mite have been identified in genus Ribes. The most studied gall mite resistance gene, designated $C e$, has been identified in gooseberry ( $R$. uva-crispa) (Knight et al. 1974, Keep et al. 1982, Brennan et al. 1993). The resistance determined by this gene is monogenic and ensures effective protection against gall mite and BRV. However, application of the gene in the development of black currants resistant to gall mite is limited. $F_{1}$ hybrids of interspecific crosses of gooseberry and blackcurrant are weakly developed and have low agronomic value. Their further use in breeding programmes is limited due to low viability and sterility (Stanys et al. 1994). As a consequence, the $C e$ gene is not common in economically important blackcurrant cultivars.

$P$ is another gene responsible for blackcurrant resistance to gall mite. It was identified in $R$. nigrum ssp. sibiricum (Anderson 1971, Jones et al. 1998, Kniazev and Ogolcova 2004). This resistance gene was determined in the cultivar 'Dainiai' bred at the Institute of Horticulture, Lithuanian Research Centre for Agriculture and Forestry (Sasnauskas et al. 2009).

Molecular markers for $\mathrm{Ce}$ gene, governing gall mite resistance, were developed using interspecific hybrids of gooseberry and blackcurrant by Brennan and colleagues (2009). We have identified a molecular marker related to $P$ gene in blackcurrant hybrids derived from cultivars with $R$. nigrum ssp. sibiricum (Mazeikiene et al. 2012).

Interspecific hybridisation resulting in black currant cultivars with natural resistance to gall mite could be one of the most effective tools to solve the problem of gall mite infection in black currant plantations. Species from genus Ribes - $R$. americanum, $R$. nigrum spp. sibiricum, $R$. uva-crispa, $R$. aureum, $R$. sanguineum, have been used as donors of resistance to various $R$. nigrum diseases and pests (Stanys et al. 2004, Siksnianas et al. 2005, Rubauskis et al. 2006, Brennan et al. 2009). However, genetic background of resistance to gall mite in species $R$. americanum, $R$. aureum, $R$. dikusha and $R$. sanguineum still remains unknown.

Therefore, the current study was focused on the application of molecular markers related to $P$ and $C e$ genes to define the origin of resistance to gall mite in $R$. americanum, $R$. aureum, $R$. dikusha and $R$. sanguineum species and to assess inheritance of gall mite resistance in the genotypes obtained by interspecific hybridization. 


\section{Materials and methods \\ Plant material}

Plants of different Ribes species maintained at a collection of Institute of Horticulture, $\operatorname{LRCAF}\left(55^{\circ} 60^{\prime} \mathrm{N}, 23^{\circ} 48^{\prime}\right.$ E) - $R$. americanum, $R$. sanguineum, $R$. dikuscha, $R$. aureum 'Corona'; $R$. nigrum ssp. sibiricum as $P$ gene donor, $R$. uva-crispa 'Bedford Yellow' as Ce gene donor, interspecific $\mathrm{F}_{3}$ hybrids of $R$. nigrum $\mathrm{x}$. americanum, $R$. nigrum $\times$. aureum, $R$. nigrum $\times R$. sanguineum; were used in the study. Fertility of interspecific $\mathrm{F}_{1}$ hybrids was weak, a small number of $F_{2}$ hybrids were planted in the field. Fertile interspecific $F_{3}$ hybrids, obtained after open pollination in the field conditions, with economically important traits were chosen for analysis of molecular markers of gall mite resistance. In 2014 and 2015, the extent of bush damage caused by C. ribis was evaluated on 5-6-year-old plants in points using 0 to 3 scale, with score 0 indicating only undamaged buds per bush, score 1 indicating one to three damaged buds, score 2 indicating four to ten damaged buds, score 3 indicating more than ten damaged buds.

Genomic DNA was extracted from $0.2 \mathrm{mg}$ of fresh leaf tissue using the CTAB-based extraction protocol by Doyle and Doyle (1990).

\section{Gene identification}

Ce gene

$\mathrm{Ce}$ gene was identified using a molecular marker based on sequence of AFLP fragment (Brennan et al. 2009). Primer set 5'TTGAGACCTCCAAGTCCTGCT3' and 5'CTTGGCTTCGTTGTTAGATGC3' for PCR fragment in 180 bp length was used. PCR was performed in a $20 \mu \mathrm{l}$ reaction volume containing $50 \mathrm{ng}$ of total DNA, $1 \mathrm{U}$ Taq DNA polymerase (ThermoScientific Ltd.), 1 Taq DNA polymerase reaction buffer, $2.5 \mathrm{mM} \mathrm{MgCl}, 0.2 \mathrm{mM}$ dNTP mix, $0.5 \mu \mathrm{M}$ each of forward and reverse primers. DNA amplification reactions were performed under the following conditions: initialization step of $5 \mathrm{~min}$ at $94{ }^{\circ} \mathrm{C}, 30 \mathrm{cycles}$ of $30 \mathrm{~s}$ at $94{ }^{\circ} \mathrm{C}, 30 \mathrm{~s}$ at $55^{\circ} \mathrm{C}, 30 \mathrm{~s}$ at $72{ }^{\circ} \mathrm{C}$ and final elongation step of 10 $\min$ at $72{ }^{\circ} \mathrm{C}$. The amplification products were separated on $1.5 \%$ agarose gel and stained with ethidium bromide. GeneRulerTM DNA Ladder Mix (Thermo Scientific Ltd.) was used as size standard. Fragments in the length of 180 $\mathrm{bp}$ of $\mathrm{Ce}$ gene were sequenced. These $180 \mathrm{bp}$ fragments were extracted from agarose gel using a NucleoSpin Extract II kit (Macherey-Nagel Ltd.), according to the manufacturer's protocol and sequenced at the DNA Sequencing Centre (Institute of Biotechnology, Vilnius University). Genamics Expression software was used for multiple sequence alignment (Corpet 1988, Thompson et al. 1994).

\section{$P$ gene}

AFLP analysis was performed according to Vos et al. (1995) method. AFLP Plant Fingerprinting Kit (Applied Biosystems Ltd.) was used for sample preparation; all procedures were performed according to the manufacturer's protocol. Two hundred ng of genomic DNA was digested with restriction endonucleases EcoRI and Tru1I (Msel) (Thermo Scientific Ltd.) and corresponding adaptors were ligated. Preamplification was carried out with standard primers EcoRI A and Msel C (205 nM each) in a $20 \mu$ reaction volume containing $4 \mu$ l of diluted restriction-ligation mix and $15 \mu$ of AFLP Amplification Core Mix (Applied Biosystems Ltd.). Preamplification conditions were as follows: $94{ }^{\circ} \mathrm{C}$ hold for 2 min followed by 20 cycles of $20 \mathrm{~s}$ at $94{ }^{\circ} \mathrm{C}, 30 \mathrm{~s}$ at $56^{\circ} \mathrm{C}$ and $120 \mathrm{~s}$ at $72{ }^{\circ} \mathrm{C}$, followed by final steps of $2 \mathrm{~min}$ at $72{ }^{\circ} \mathrm{C}$ and $30 \mathrm{~min}$ at $60^{\circ} \mathrm{C}$.

PCR

Selective PCR amplification was carried out under the same reaction conditions. The difference was that $2 \mu$ of diluted pre-amplification template was added and EcoRI and Msel primers were used at $50 \mathrm{nM}$ and $250 \mathrm{nM}$ concentration, respectively. Selective amplification was performed using the following programme: an initial cycle of $30 \mathrm{~s}$ at $94{ }^{\circ} \mathrm{C}, 30 \mathrm{~s}$ at $65^{\circ} \mathrm{C}$ and $80 \mathrm{~s}$ at $72{ }^{\circ} \mathrm{C}$, followed by 10 cycles of $30 \mathrm{~s}$ at $94{ }^{\circ} \mathrm{C} 30 \mathrm{~s}$ at 65 to $56{ }^{\circ} \mathrm{C}, 1{ }^{\circ} \mathrm{C}$ per cycle, $80 \mathrm{~s}$ at $72{ }^{\circ} \mathrm{C}$; followed by 23 cycles of $30 \mathrm{~s}$ at $94{ }^{\circ} \mathrm{C}, 30 \mathrm{~s}$ at $55^{\circ} \mathrm{C}$ and $80 \mathrm{~s}$ at $72{ }^{\circ} \mathrm{C}$, final step of $5 \mathrm{~min}$ at 72 ${ }^{\circ} \mathrm{C}$. Samples were prepared for capillary electrophoresis by mixing $1 \mu \mathrm{l}$ of the PCR product with $8.88 \mu \mathrm{l}$ of $\mathrm{Hi}-\mathrm{Di}$ formamide and $0.12 \mu \mathrm{l}$ of Gene Scan 500 LIZ ladder (Applied Biosystems, Ltd.), and analysed using a 3130 Genetic Analyzer (Applied Biosystems Ltd.). Heterogeneity between recombination frequencies (AFLP marker and resistance to gall mite in the field condition) in the four populations was examined using the chi-squared test in JoinMap 4 (Van Ooijen 2011). 


\section{Results}

We analysed the presence of $\mathrm{Ce}$ gene in plants of 5 Ribes species (Fig. $1 \mathrm{~A}$ ), using a molecular marker developed by Brennan et al. (2009). The analysis established that PCR product of expected size was identified in gooseberry 'Bedford Yellow' characteristic of the marker of gene Ce. R. aureum 'Corona' and R. sanguineum plants had marker of the gene $C e$ that was at the identical position as in the case of $R$. uva-crispa plants (Fig. $1 \mathrm{~A}$, lane 2, 5 and 6). Ce marker was absent in genomes of $R$. americanum and $R$. dikuscha and in R. nigrum ssp. sibiricum (Fig. $1 \mathrm{~A}$, lane 1,3 and 4). Identification of molecular marker related to the $C e$ gene in wild type $R$. sanguineum and $R$. aureum enabled us to assume the presence of similar genomic region including resistance gene homologous to $\mathrm{Ce}$ gene of R. uva-crispa. Homology of molecular marker sequence was verified by sequencing the specific 180 bp size fragments, similar to molecular marker for Ce gene in R. sanguineum, R. aureum and R. uva-crispa 'Bedford Yellow' (Fig. 1 B). Nucleotide sequences of R. uva-crispa 'Bedford Yellow' from our collection were $100 \%$ identical, indicating the inheritance of the marker specific to gooseberry $C e$ gene by the interspecific $\mathrm{F}_{1}$ hybrid. In addition, strong nucleotide sequence homology $90.0 \%$ and $88.3 \%$ was found between the sequences of the Ce molecular marker of gooseberry and $R$. sanguine um or gooseberry and $R$. aureum, respectively (Fig. $1 \mathrm{~B}$ ). Therefore, it is possible that resistance to gall mite in $R$. aureum and $R$. sanguineum is determined by the Ce gene like in gooseberry.

A

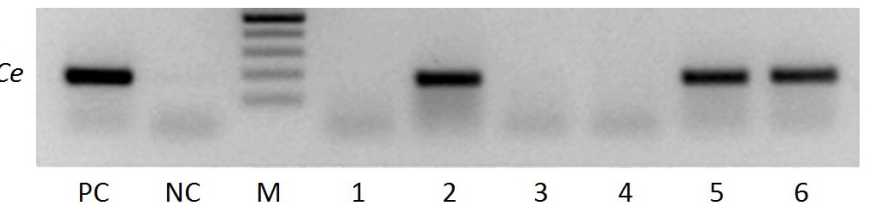

B

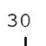

60

R. aureum TTACCGCAGATACAAGGTGAAGCTAGTTTACTTTATGAACCCGAGATTTGGAAGATATAT

R. sanguineum TTACCGCAGATACAAGGTGAAGCTCATTCACCATTTGAACCCGAAGCATGGAAGATGTAT

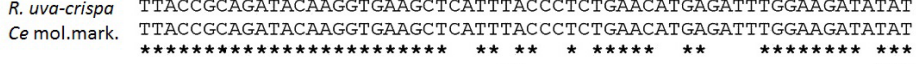
90

R. aureum GTAGATGGGGCCTCGAATAGAAAGGGAGCATGATCAGGAATAGTTCTATAGTCCGCCTAA R. sanguineum GTGGACGGGTCCTCGAACAGCAGGAGAGTTGGAGCAGGAATAGTTCTAGTGTCATAAGAA

R. uva-crispa GTAGATGGGGCCTCGAATAGCAAGAGAGCCGAAGCAGGAATAGTTCTAGTGTCATAAGAA

ce mol.mark. GTAGATGGGGCCTCGAATAGCAAGAGAGCCGAAGCAGGAATAGTTCTAGTGTCATAAGAA

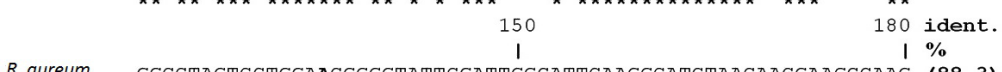

R. aureum GGCCTAGTCCTGGAACGGGGTATTCGATTGGCATTCAAGGCATCTAACAACGAAGCCAAG $(\mathbf{8 8}, \mathbf{3})$

R. sanguineum GGCCTAGTCCTGGAGCGGGGTATTCGATTGGCATTCAAGGCATCTAACAACGAAGCCAAG $(90,0)$
$R$. uva-crispa

R. uva-crispa GGCCTAGTCCTGGAGCGGGGTATTCGATTGGCATTCAAGGCATCTAACAACGAAGCCAAG (100)

ce mol.mark. GGCCTAGTCCTGGAGCGGGGTATTCGATTGGCATTCAAGGCATCTAACAACGAAGCCAAG Control

Fig. 1. Molecular marker for gene $C e$ in different Ribes species. A. Amplified PCR fragment in 180 bp length; B. Ce molecular marker sequences in Ribes species, compared to Brennan et al. 2009. PC = positive gene control (PCR with DNA of plasmids with insert of Ce marker sequence), NC = negative control (PCR mix without DNA template), $\mathrm{M}=$ size standard 100-500 bp (O'GeneRuler SM1173, Thermo Scientific Ltd.), $1=R$. americanum, $2=R$. aureum, $3=R$. dikuscha $4=R$. nigrum ssp. sibiricum, $5=R$. sanguineum, $6=R$. uva crispa 'Bedford Yellow'

Electropherograms of the AFLP fragments with the marker related to $P$ gene are shown in Fig. 2. This marker was developed at our laboratory (Mazeikiene et al. 2012). The fragment $107 \mathrm{bp}$ in length demonstrates that the marker was present in $R$. nigrum spp. sibiricum, $R$. americanum and $R$. aureum 'Corona'. The molecular marker for gene $P$ was not identified in species of $R$. sanguineum, R. dikuscha and $R$. uva-crispa 'Bedford Yellow' (Fig. 2). 


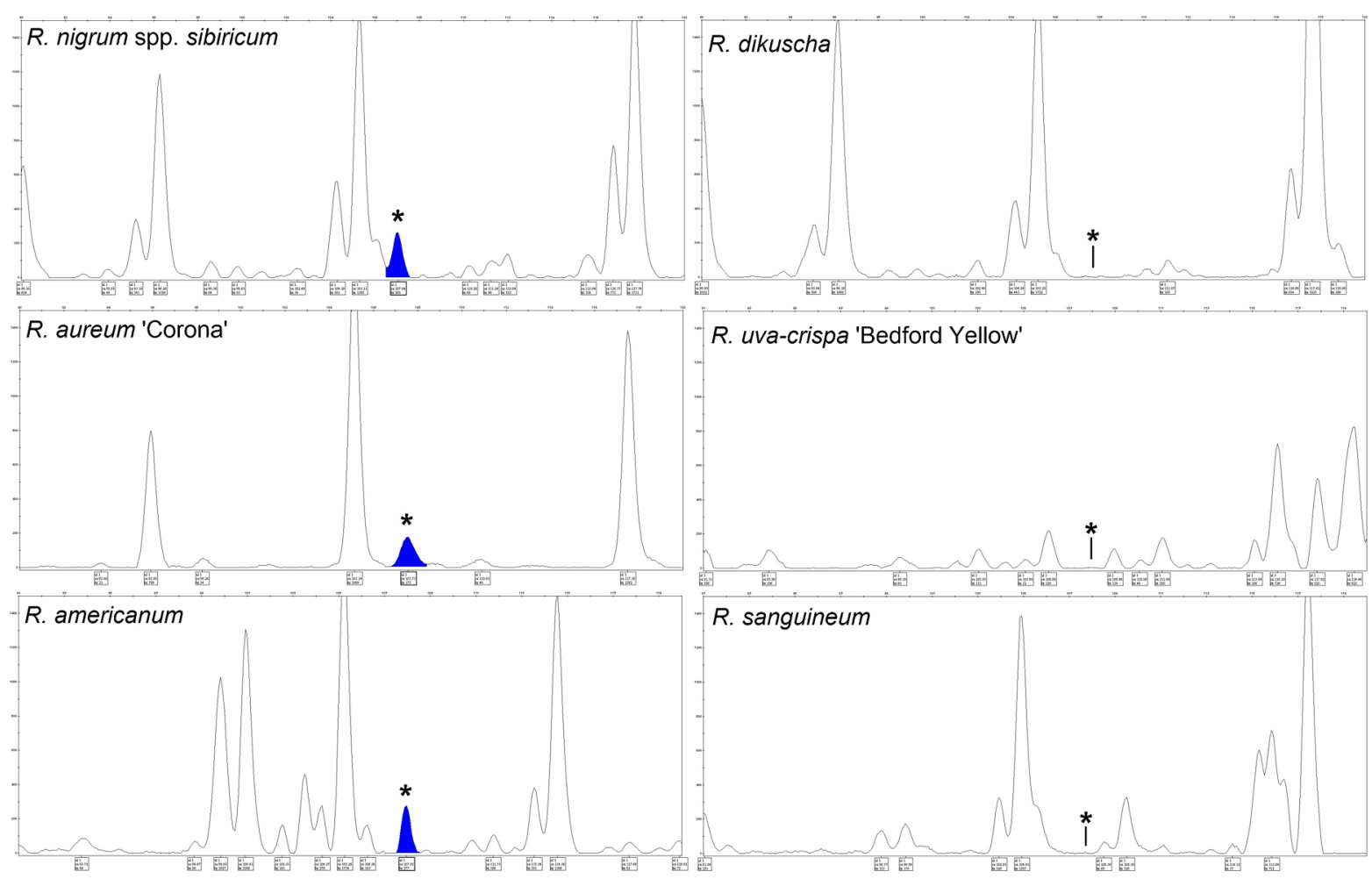

Fig. 2. Electropherogram of $107 \mathrm{bp}$ AFLP marker related to dominant $P$ gene in different Ribes species. ${ }^{*}=$ location of molecular marker, related to $P$ gene

Interspecific $F_{3}$ hybrids were obtained after open pollination of $F_{1}$ and $F_{2}$ hybrids in the field conditions. Field resistance to gall mite of interspecific $\mathrm{F}_{3}$ hybrids from families $R$. nigrum $\times R$. sanguineum, $R$. nigrum $\times R$. aureum and $R$. nigrum $\times R$. americanum was evaluated. Hybrids with score 0 were considered as resistant, and those with scores 1,2 or 3 were considered as susceptible. Hybrids resistant to gall mite segregated at 1:1 ratio in $F_{3}$ generation of $R$. nigrum $\times R$. americanum and $R$. nigrum $\times R$. sanguineum. Interspecific $F_{3}$ hybrids obtained from the cross $R$. nigrum $\times R$. aureum segregated at 3:1 ratio (Table 1 ).

Table 1. Resistance of interspecific $\mathrm{F}_{3}$ hybrids of Ribes genus to gall mite in the field conditions

\begin{tabular}{lccccc}
\hline & $\begin{array}{c}\text { Number of } \\
\text { hybrids }\end{array}$ & $\begin{array}{c}\text { Resistance to gall mite in field } \\
\text { condition } \\
\text { Cross combination* }\end{array}$ & Resistant, no. Susceptible, no. & $\begin{array}{c}\text { X2 (expected } \\
\text { segregation ratio) }\end{array}$ & $p$ \\
\hline R. nigrum $\times$ R. sanguineum & 45 & 26 & 19 & $1.09(1: 1)$ & $>0.25$ \\
R. nigrum $\times$ R. aureum & 40 & 27 & 13 & $1.20(3: 1)$ & $>0.25$ \\
R. nigrum $\times$ R. americanum & 33 & 15 & 18 & $0.27(1: 1)$ & $>0.50$ \\
\hline * . progen
\end{tabular}

The results of genetic analysis of gall mite resistance in $R$. nigrum $\times R$. americanum, $R$. nigrum $\times R$. aureum and $R$. nigrum $\times R$. sanguineum interspecific hybrids based on the presence of the $107 \mathrm{bp} \mathrm{AFLP} \mathrm{and} \mathrm{of} \mathrm{the} 180 \mathrm{bp}$ PCR molecular markers are shown in the Fig. 3. 


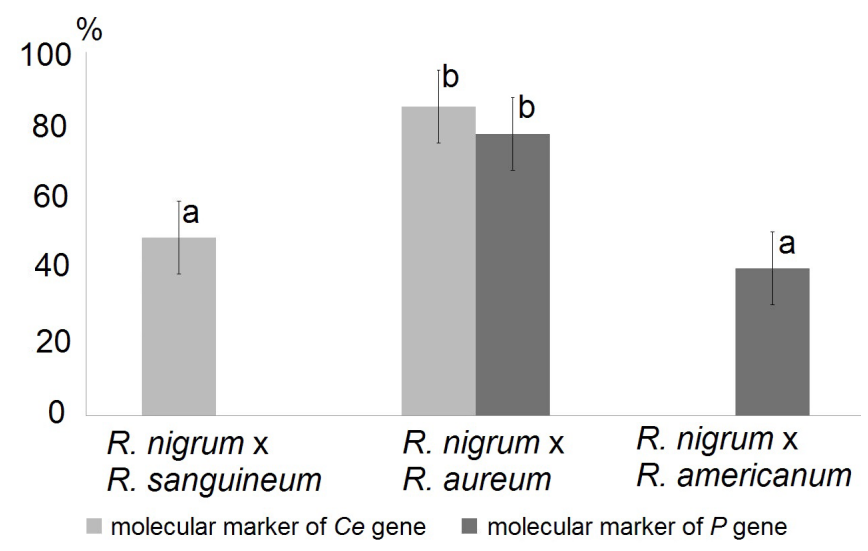

Fig. 3. Molecular markers related to resistance to gall mite in interspecific $\mathrm{F}_{3}$ Ribes hybrids

Molecular marker of $P$ gene was found in the genome of interspecific $\mathrm{F}_{3}$ hybrids obtained after open pollination of $R$. nigrum $\times R$. americanum and $R$. nigrum $\times R$. aureum. The presence of the molecular marker of $C e$ gene in $R$. nigrum $\times R$. sanguineum and $R$. nigrum $\times R$. aureum $\mathrm{F}_{3}$ hybrids was confirmed in the field conditions. Resistance to gall mite was determined by $C$ e gene in $48.9 \%$ hybrids in $R$. nigrum $\times R$. sanguineum family. The molecular marker of $P$ gene was present in $40.5 \%$ genotypes of $R$. nigrum $\times$ R. americanum. Molecular markers of $P$ and $C e$ genes were present in $R$. nigrum $\times R$. aureum hybrids ( 77.5 and $85.0 \%$, respectively). $75.0 \%$ promising hybrids with a pyramidal resistance to gall mite obtained in cross combination $R$. nigrum $\times R$. aureum are a valuable source of resistance for future breeding.

\section{Discussion}

Two genes responsible for resistance to $C$. ribis have been known to date: $P$ gene has been identified in $R$. nigrum spp. sibiricum (Anderson 1971) and Ce gene is characteristic of R. uva-crispa (Knight et al. 1974).

Resistance of $R$. sanguineum to gall mite and mildew has been reported by Keep (1986). This species was used as a donor of resistance in heredity research (Keep 1981, Goodman et al. 1987, Siksnianas et al. 2008). However, genetic background of the resistance of $R$. sanguineum has not been assessed previously. Identification of molecular marker for the $C e$ gene in wild type $R$. sanguineum and $R$. aureum in our analysis enabled us to assume the presence of similar genomic region including resistance gene homologous to Ce gene of $R$. uva-crispa. It was shown earlier, that $R$. dikuscha is immune to reversion virus (Adams and Tresh 1987); however, we did not establish Ce marker in its genome. $P$ resistance is specific to $R$. nigrum ssp. sibiricum and $R$. nigrum cultivars 'Rus', 'Dainiai', 'Ben Lomond' and 'Titania' (Anderson 1971, Mazeikiene et al. 2012), therefore marker for Ce gene was not established in these plants. In gooseberry, the resistance to gall mite is controlled by a single $\mathrm{Ce}$ gene (Knight et al. 1974). Interspecific $R$. nigrum $\times R$. uva-crispa hybrids inherit $C e$ gene at a 1:1 ratio in $\mathrm{F}_{1}$. The main problem is that hybrids are mostly infertile and the majority of the R. uva-crispa, $R$. sanguineum or $R$. aureum genome is lost during the earliest stages of backcrossing (Keep 1986, Siksnianas et al. 2008). $F_{1}$ hybrids of interspecific crosses of gooseberry and blackcurrant are weakly developed and have low agronomic value. Their further use in breeding programmes is limited due to infertility and low viability (Stanys et al. 1994). Interspecific hybrids can improve fertility after open pollination in the field conditions in $\mathrm{F}_{2}$ generation, and economically important traits improve in $F_{3}$. As a result, we used promising $F_{3}$ hybrids in our study. Early diagnostics of valuable traits in $F_{1}$ progeny is crucial in the breeding process.

In this study, the presence of the molecular marker for dominant $P$ gene was assessed in Ribes species and $\mathrm{F}_{3}$ interspecific hybrids. Previously, traits of resistance to gall mite were identified in $R$. nigrum spp. sibiricum (Anderson 1971, Jones et al. 1998), R. americanum and R. aureum (Barney and Hummer 2005, Rubauskis et al. 2006); however, genetic background of the resistance was unknown. Our results suggest that resistance to gall mite in $R$. nigrum spp. sibiricum, $R$. americanum and $R$. aureum is determined by the dominant $P$ gene. Molecular markers 
I. Mazeikiene et al. (2017) 26: 111-117

linked to both $P$ and $C e$ genes are found in the genome of $R$. aureum. The molecular marker for $P$ gene was not observed in $R$. dikuscha, $R$. sanguineum and $R$. uva-crispa. Plants of $R$. dikuscha are resistant to gall mite in the field conditions (Trajkovski and Pääsuke 1976); however, in our study molecular markers for $C e$ and $P$ genes were absent.

It was established that $P$ gene, derived from $R$. nigrum spp. sibiricum, responsible for blackcurrant resistance to gall mite was dominant (Anderson 1971) and 1:1 segregation ratio of resistance to gall mite in hybrids was observed (Mazeikiene et al. 2012). In our study, inheritance of gall mite resistance trait derived from $R$. americanum fitted the expected 1:1 ratio in $\mathrm{F}_{3}$ hybrids $R$. nigrum $\times R$. americanum, as well. Therefore, we may conclude that $P$ gene is in homozygous state in $R$. americanum. $R$. americanum is resistant to diseases and it flowers later compared to other Ribes species. In temperate climate zone, late flowering reduces the risk of currant flower damage during spring frosts. It was shown that early flowering and adaptivity in Ribes species are determined by cytoplasm, and therefore interspecific $R$. nigrum $\times R$. americanum $\mathrm{F}_{1}$ hybrids and their progeny were open pollinated in the field conditions with pollen from $R$. nigrum cultivars with low frequency of $P$ gene (Keep 1986, Siksnianas et al. 2005). Inheritance of resistance to gall mite remained at 1:1 ratio in $F_{3}$ generation derived from this cross combination. Similar data were observed while studying inheritance of $\mathrm{Ce}$ gene. Inheritance of resistance to gall mite derived from $R$. sanguineum fitted the expected 1:1 ratio in $R$. nigrum $\times$. sanguineum $\mathrm{F}_{3}$ hybrids. Blackcurrant hybrids with $R$. nigrum cytoplasm flowered earlier, and their progeny was open pollinated by $R$. nigrum hybrids or species. In our research, $R$. aureum species is characterized by the pyramidal ( $P$ and $C e$ genes) resistance to gall mite. In $R$. nigrum $\times R$. aureum cross combination, gall mite resistance genes $P$ and $C e$ remained in heterozygous state in $\mathrm{F}_{3}$ progeny. Gall mite resistance ratio remained at 3:1 in $R$. nigrum $\times R$. aureum $\mathrm{F}_{3}$ hybrids, such ratio is favourable for the creation of resistant cultivars with other economically important traits.

Gall mite resistance remains a high priority for most currant breeding programmes. Distant hybridisation between different species provides qualitatively new material for currant breeding. $R$. uva-crispa, $R$. sanguineum and $R$. aureum as donors of $\mathrm{Ce}$ gene and $R$. sibiricum, $R$. americanum and $R$. aureum as donors of $P$ gene may be effectively used as source material for gall mite resistance in the future breeding programmes. Early diagnosis of these genes allows selecting promising hybrids, and enables creating novel varieties with complex resistance to gall mite.

Our results suggest that resistance to gall mite in $R$. sanguineum is determined by $C e$ gene. Resistance to gall mite in $R$. americanum is determined by the dominant $P$ gene as in $R$. nigrum spp. sibiricum. Resistance to gall mite in $R$. aureum is controlled by two genes $C e$ and $P$. The presence of molecular markers and resistance to gall mite in $R$. nigrum $\times R$. americanum and $R$. nigrum $\times R$. sanguineum $\mathrm{F}_{3}$ hybrids, obtained after open pollination in the field conditions of $\mathrm{F}_{1}$ and $\mathrm{F}_{2}$ hybrids, fitted the expected segregation ratio 1:1. $R$. americanum $\times R$. aureum $\mathrm{F}_{3}$ hybrids, obtained after open pollination in the field conditions of $F_{1}$ and $F_{2}$ hybrids, fitted 3:1 ratio. Pyramiding of the $C e$ and $P$ genes in breeding programs will produce hybrids with natural resistance to gall mite, thus resulting in unique breeding material.

\section{References}

Adams, N.A. \& Tresh, J.M. 1987. Virus and viruslike diseases of Ribes (gooseberry and black and red currant). In: Converse R.H. (ed.). Virus disease of small fruits and grapevines. Berkeley: University of California. p. 127-162.

Anderson, M.M. 1971. Resistance to gall mite (Phytoptus ribis Nal.) in the Eucoreosma section of Ribes. Euphytica 20: 422-426. https://doi.org/10.1007/BF00035668

Barney, D.L. \& Hummer, K.E. 2005. Currant, goosberries and jostaberries - a guide for growers, marceters and researchers in North America. NY Binghamptom: Haworth Press. 266 p.

Brennan, R., Jorgensen, L., Gordon, S., Loades, K., Hackett, C. \& Russell, J. 2009. The development of a PCR-based marker linked to resistance to the blackcurrant gall mite (Cecidophyopsis ribis Acari: Eriophyidae). Theoretical and Applied Genetics 118: 205211. https://doi.org/10.1007/s00122-008-0889-x

Brennan, R.M., Lanham, P.G. \& McNicol, R.J. 1993. Ribes breeding and research in the UK. Acta Horticulturae 352: 267-275. https://doi.org/10.17660/ActaHortic.1993.352.38

Corpet, F. 1998. Multiple sequence alignment with hierarchical clustering. Nucleic Acids Research 16: 10881-10890. https://doi.org/10.1093/nar/16.22.10881

Doyle, J.J. \& Doyle, J.L. 1990. A rapid total DNA preparation procedure for fresh plant tissue. Focus 12: 13-15.

Goodman, F.L., Hauptli, H., Crossway, E., \& Knauf, V.C. 1987. Gene transfer in crop improvement. Science 236: 48-54. https://doi.org/10.1126/science.236.4797.48

Jones, A.T., Brennan, R.M., McGavin, W.J. \& Lemmetty, A. 1998. Galling and reversion disease incidence in a range of blackcurrant genotypes, differing in resistance to the blackcurrant gall mite (Cecidophyopsis ribis) and blackcurrant reversion disease. Annals of Applied Biology 133: 375-384. https://doi.org/10.1111/j.1744-7348.1998.tb05837.x 
Jones, A.T. 2000. Black currant reversion disease - the probable causal agent, eriophyid mite vectors, epidemiology and prospects for control. Virus Research 71: 71-84. https://doi.org/10.1016/S0168-1702(00)00189-1

Keep, E. 1981. Ribes glutinosum and Ribes sanguineum as donors of resistance to American gooseberry mildew in black currants breeding. Euphytica 30: 197-202. https://doi.org/10.1007/BF00033678

Keep, E. 1986. Cytoplasmic male sterility, resistance to gall mite and mildew, and season of leafing out in black currants. Euphytica 35: 843-855. https://doi.org/10.1007/BF00028592

Keep, E., Knight, V.H. \& Parker, J.H. 1982. Progress in the integration of characters in gall mite resistant black currants. Journal of Horticultural Science 57: 189-196. http://dx.doi.org/10.1080/00221589.1982.11515039

Kniazev, S.D. \& Ogolcova, T.P. 2004. Inheritance of resistance to gall mite evaluation of different cross combination. In: Kniazev S.D. \& Ogolcova, T.P. (eds.). Black currant breeding at present. Orel: OrelGAU. 238 p. (in Russian).

Knight, R.L., Keep, E., Briggs, J.B. \& Parker, J. 1974. Transference of resistance to black currant gall mite Cecidophyopsis ribis, from goosebery to black currant. Annals of Applied Biology 76: 123-130. https://doi.org/10.1111/j.1744-7348.1974.tb01362.x

Mazeikiene, I., Bendokas, V., Stanys, V. \& Siksnianas, T. 2012. Molecular markers linked to resistance to the gall mite in blackcurrant. Plant Breeding 131: 762-766. http://dx.doi.org/10.1111/j.1439-0523.2012.01995.x

Rubauskis, E., Strautina, S. \& Surikova, V. 2006. Importance of cultivar choise in preventing infestacion by the black currant gall mite (Cecidophyopsis ribis WESTW.) on black currant plantations. Journal of Fruit and Ornamental Plant Research 14: 209-215.

Sasnauskas, A., Trajkovski, V., Strautina, S., Tikhonova, O., Šikšnianas, T., Rubinskiene, M., Viškelis, P., Lanauskas, J., Valiuškaitė, A., Rugienius, R. \& Bobinas, Č. 2009. Evaluation of blackcurrant cultivars and perspective hybrids in Lithuania. Agronomy Research 7: 737-743.

Siksnianas, T., Stanys, V., Staniene, G., Sasnauskas, A. \& Rugienius, R. 2005. American black currant as donor of leaf disease resistance in black currant breeding. Biologija 3: 65-68.

Siksnianas, T., Staniene, G., Stanys, V. \& Sasnauskas, A. 2008. Ribes sanguineum Pursh. as donor of leaf fungal disease resistance in blackcurrant breeding. Biologija 54: 79-82. https://doi.org/10.2478/v10054-008-0015-7

Stanys, V., Shikshnianas, T. \& Staniene, G. 1994. Embryo development and embryo rescue within the genus Ribes. Norwegian Journal of Agricultural Sciences 9: 95-104.

Stanys, V., Staniene, G., Shikshnianas, T. \& Bobinas, C. 2004. Interspecific Hybridisation in Ribes Genus. Proceedings of the XIth Eucarpia Symposium on Fruit Breeding and Genetics. Acta Horticulturae 663: 861-864. https://doi.org/10.17660/ActaHortic.2004.663.155

Šutic, D.D., Ford, R.E. \& Tošic, M.T. 1999. Virus Diseases of Ribes spp. In: Šutic, D.D., Ford, R.E. \& Tošic, M.T. (eds.). Handbook of plant virus diseases. CRC Press, Boca Raton, FL. p. 457-475.

Thompson, J.D., Higgins, D.G. \& Gibson, T.J. 1994. CLUSTAL W: improving the sensitivity of progressive multiple sequence alignment through sequence weighting, positions-specific gap penalties and weight matrix choices. Nucleic Acids Research 22: 46734680. https://doi.org/10.1093/nar/22.22.4673

Trajkovski, V. \& Pääsuke, R. 1976. Resistance to Sphaerotheca mors-uvae (Schw.) Berk. in Ribes nigrum L. 5. studies on breeding black currants for resistance to Sphaerotheca mors uvae (Schw.) Berk. Swedish Journal of Agricultural Research 6: 201-214.

Van Ooijen, J.W. 2011. Multipoint maximum likelihood mapping in a full-sib family of an out breeding species. Genetical Research 93: 343-349. http://dx.doi.org/10.1017/S0016672311000279

Vos, P., Hogers, R., Bleeker, M., Reijans, M., van de Lee, T., Hornes, M., Frijters, A., Pot, J., Peleman, J., Kuiper, M. \& Zabeaum, M. 1995. AFLP: a new technique for DNA fingerprinting. Nucleic Acids Research 23: 4407-4414.

https://doi.org/10.1093/nar/23.21.4407 